\title{
Development and implementation of algorithms of building structure engineering calculations for shear fraction under pressing-through.
}

\author{
Tetiana Dmytrenko ${ }^{1, *}$, Oleksandr Semko $^{1}$, Andrii Dmytrenko ${ }^{1}$, Tetiana Derkach $^{1}$, and \\ Olena Voskobiinyk ${ }^{1}$ \\ ${ }^{1}$ Poltava National Technical Yuri Kondratyuk University, Pershotravnevyj Ave, 24, Poltava, \\ 36011, Ukraine
}

\begin{abstract}
Development of calculating algorithms for designed and patented constructive solutions for beamless monolithic slab and concrete reinforced column connection in the form of software program is presented in this article. Also a mathematical model for the constructive solutions was created using finite elements method. A theoretical part of the research includes engineering technique for the connection nodes between monolithic concrete slab and reinforced concrete column in stress strain state. A technical goal is simplifying and reliability increasing of loading capacity of the junction and assembly work facilitation along with reducing building frame costs. To perform testing of connection nodes between monolithic reinforced concrete beamless non-bearing slab and reinforced concrete column for shear existing calculating algorithm was improved using the designed formula. A connection node for a shear along the column body calculation according to the technique was also implemented as a software program. A technique for calculating a connection node between monolithic beamless non-capital concrete reinforced slab and concrete reinforced columns was developed. Visual Basic for Applications was used to automate calculating of the connection nodes for shear. The research results have been implemented into practical design and calculation during extension of manufacturing building of Skvira confectionary shop in Skvira settlement.
\end{abstract}

\section{Introduction}

Nowadays there are a great number of junction's variations between columns and slabs. The most popular are usage of confinement or rigid reinforcement in the slab and junctions with capitals. However these approaches have some weaknesses, as high material capacity, labor intensity, complexity of calculation and design. [1,2].

Computer technology using during the engineering calculations performing gives an opportunity to increase the structure's reliability and reduce a designing period. It is necessary to develop a calculation algorithm and it's automation to perform beam-less monolithic slabs calculations.

Usage of steel rectangular pipes, filled by concrete, allows combining of concrete (reinforced concrete) and steel constructions advantages with mutual deficiencies compensation [1], [3].

\footnotetext{
* Corresponding author: dmitr_tat@ukr.net
} 


\section{Analysis of the recent research}

Development and application issues of building constructions of monolithic slabs nodal connection calculations using up-to-date computer technologies were investigated by Horodetskyi D.O., Horodetskyi O.S. [2], Perelmuter A.V. [4], Shymkovych D.H. [5] and others [3], [6, 7].

It is necessary to develop a calculation algorithm for monolithic slab under forcing through and automation of the process to provide engineering calculations accuracy.

\section{Problem}

Punching shear may occur at a column and ceiling junction under load at failure.

Creating a real calculation model, that allows to describe construction resistance against shear effect along with inflection is one of the most complex tasks in reinforced concrete theory. That is why during monolithic beamless slabs design bursting calculation was done using methods for splitted calculating of oblique sections on shear forces and bending moment's performance [8].

There for an assumption about elastic behavior of concrete at forcing through zone under loads close to the boundary shows real work of a junction.

\section{Main part}

While solving the task a new construction solution of composite reinforced concrete columns nodes connection with a monolithic reinforced concrete beamless slab was designed and patented:

- design of knot in which monolithic reinforced concrete overlapping joins to composite reinforced concrete columns with use of anchor bending's which are welded to composite reinforced concrete columns (Figure 1) [9].

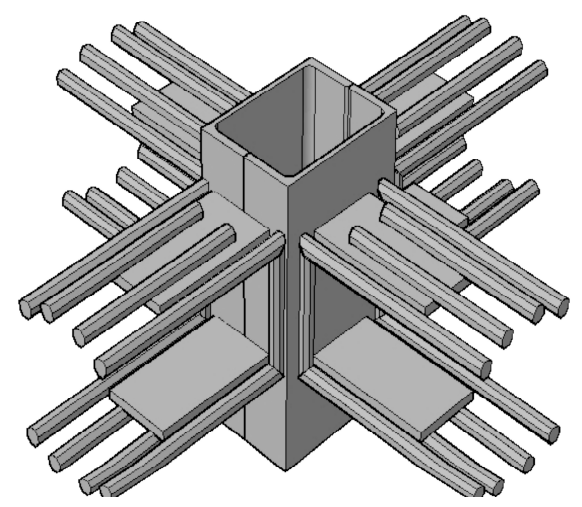

Fig. 1. Metal constructions of a monolithic girder beamless node connection with columns made of beam channels.

- node construction, where monolithic reinforced concrete floor slap is connected to composite column using anchoring bendings, which are welded to composite columns. It provides local stability of a wall of a channel (figure 2) [10]. 


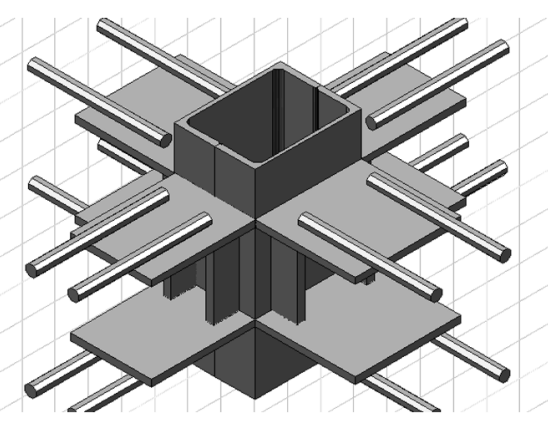

Fig. 2. Metal designs of knot of connection the composite reinforced concrete of columns from channels from a monolithic reinforced concrete girder less a plate

- design of knot in which column bore through openings for drawing of fittings. Diameter of openings is at $3 \mathrm{~mm}$ more than the size of fittings. Fittings settle down in two directions, and one above other (Figure 3) [11].

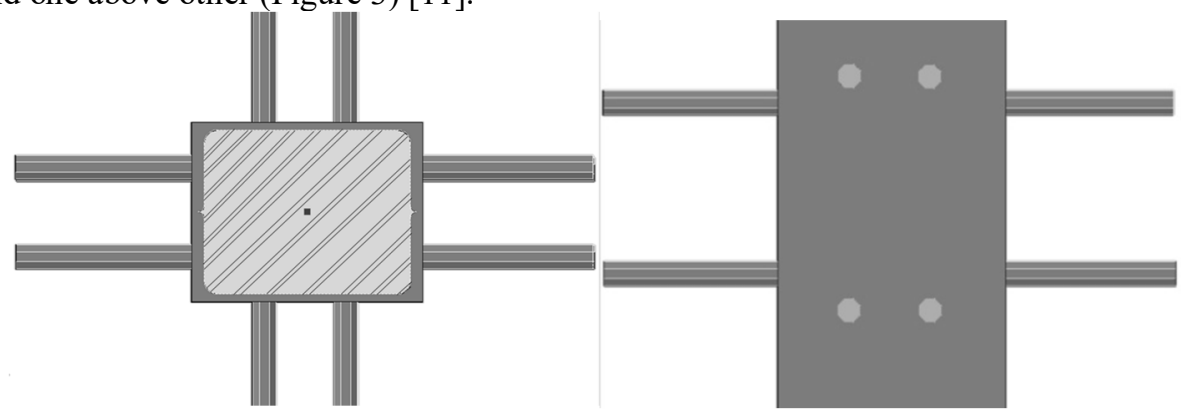

Fig. 3. The scheme of knot of connection monolithic girder less overlapping's with composite reinforced concrete columns from channels

Development of an algorithm of calculation of knots of connection monolithic reinforced concrete girder less overlapping's with composite reinforced concrete a column was carried out step by step:

Stage 1 - Theoretical research

- Analysis of existing design solutions of connection nodes between beamless monolithic slab and reinforced concrete column

- Defining features of connection nodes between beamless monolithic slab and reinforced concrete column

- Research for new design solutions of connection nodes between beamless monolithic slab and reinforced concrete column

- Calculation of reinforcing rods in connection nodes between beamless monolithic slab and reinforced concrete column

- Calculation and design slabs under bursting at the location of the columns within the slab

- Analysis of existing calculation procedures solutions of connection nodes between beamless monolithic slab and reinforced concrete column

- Analysis calculation procedures for the shear under bursting

- Calculation of connection nodes between beamless monolithic slab and reinforced concrete column using finite element method

- Calculation model design by finite element method 
- Stress-strain state of the connection nodes numerical research by the finite elements method

- Gusset calculation for composite girder connection node between beamless monolithic slab and reinforced concrete column under bursting

Stage 2 - Experimental research

- The nodal connections durability research for the tension with filling the columns with concrete

- Research of the connection node durability for the tension without filling the columns with concrete

- Research of the reinforcement influence on connection durability without using gussets

- Investigation of bearing capacity of the node connection without using gussets

- Investigation of bearing capacity of the node connection using gussets

- Design of the calculation procedure of the node connections monolithic reinforced concrete beamless overlap with the composite reinforced concrete column

Stage 3 - Calculation algorithm development

- Algorithm of the monolithic reinforced overlap for the share under bursting calculation according to Euro code.

- Algorithm of connection nodes test between monolithic beamless non-capital overlap and reinforced concrete column for the share (according to the introduced procedure)

- To design calculation algorithms of monolithic slab experimental research of suggested new connection nodes constructions (Figure 4) was performed to detect the nature of their destruction and load capacity. A mathematical model of stress-strain state of the connections was also created along with calculating by finite elements method.

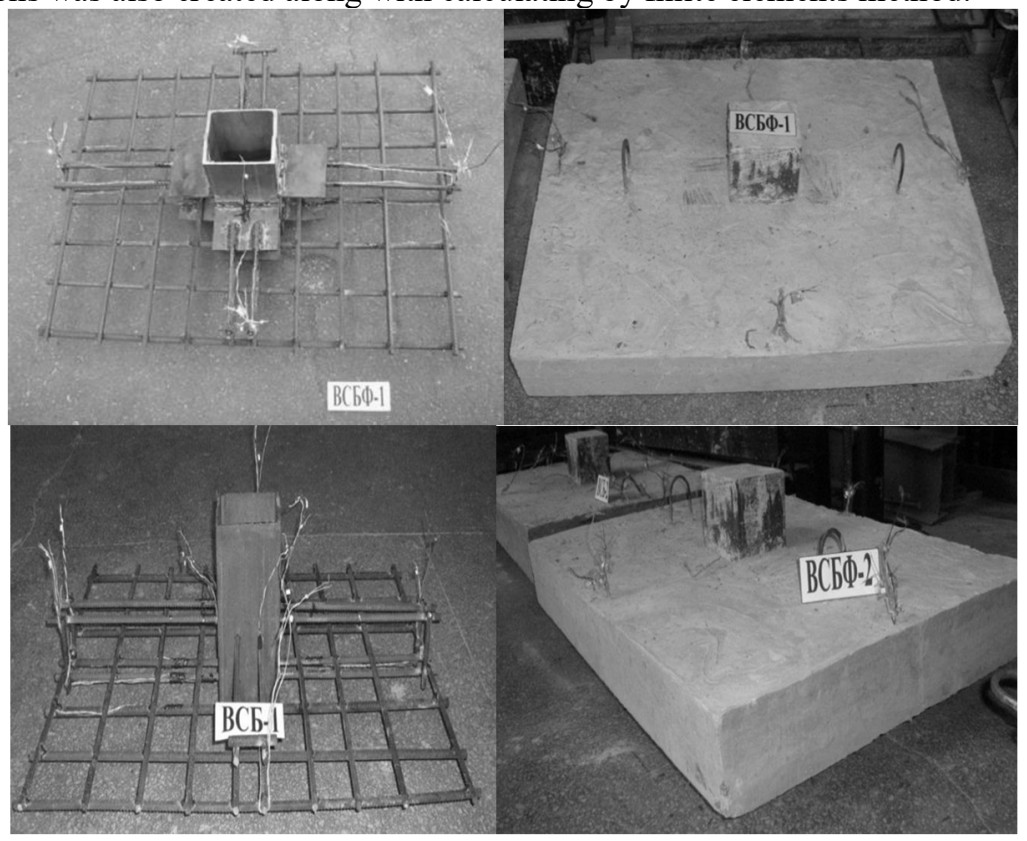

Fig. 1. Introduced new design decisions for connection nodes between monolithic concrete slab and reinforced concrete columns

To compare experimental models with mathematical ones of the nodal connections between a beamless monolithic slab and a composite column computer programs were used. They allowed to decrease a number of full-scale experiments (Femap version 8.1 (2001) as a pre- and postprocessor for MSC.Nastran. Educational demo version SDRC- 
Femap 8.1a S/N 000-00-00-demo-406F-00000000) was also used [12].

To perform constructions stress-state analysis by finite element method a calculation schema of nodes junction between beamless monolithic reinforced concrete slab and reinforced concrete column was introduced (figure 5).

As a boundary condition for the connection node, an embedding is done at the base with the command Model $\rightarrow$ Constraint On Surface. Applied load is equal to $100 \mathrm{\kappa H}$.

Necessary to mention, that the model isn't enough accurate because different type elements are connected in the node [13].

4-nodes and tetrahedron type finite elements were used to calculate reinforced concrete constructions (figure 6).

Beamless monolithic reinforced concrete slab and reinforced concrete column connection node stress-state calculation was used to compare numerical and experimental research results. The construction destruction is supposed to happen at pyramid bursting area [5].

During experiment was observed a destruction along the compressed area caused by crushing concrete over the cracks that formed the body in the form of a truncated pyramid. The element stress-state under crushing concrete over the cracks features are reinforcement and concrete deformation concentrations zones (figure 7). Concrete deformation zone is could be found next to the top of the crack. Concentration of longitudinal reinforcement deformation zone is at intersection points with the crack, that makes bursting pyramid.

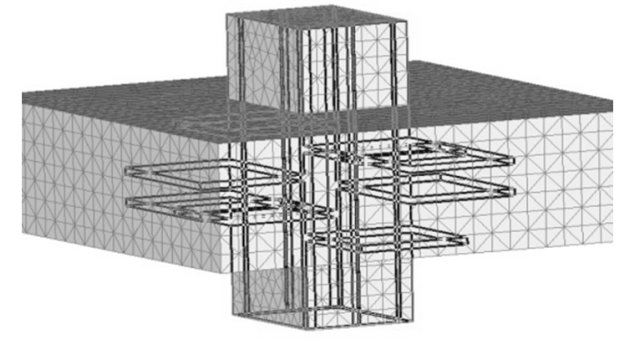

Fig. 5. A calculation schema of nodes junction between beamless monolithic reinforced concrete slab and reinforced concrete column was introduced
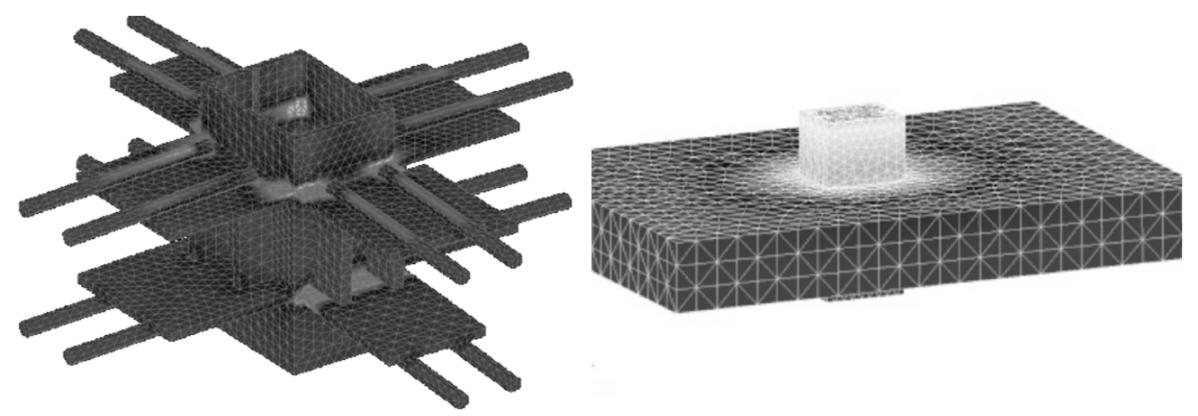

Fig. 6. A graphic representation of the deflected mode calculations results using final elements procedure

During the experiment $c / h_{0}$ ratio influence at load bearing capacity of the sample was analyzed. It was performed in planes ZX and ZY. The sample performance in plane ZX is better than in ZY plane. Accordingly $c / h_{0}$ ratio in ZX plane is less. In other words load bearing capacity is decreased for $22 \%$ under $c / h_{0}$ ratio increasing (table 1 ).

Based on the performed theoretical and field experiments calculation methodology for connection nodes between beamless monolithic concrete slab and reinforced concrete column was created. 
Table 1. Experiment input according to VSB series samples

\begin{tabular}{|c|c|c|c|c|c|}
\hline Plane & Gage & $c / h_{0}$ & $\begin{array}{c}\text { The force at which } \\
\text { fracture appeared } \\
Q, \mathrm{kN}\end{array}$ & $\begin{array}{c}\text { Destructive } \\
\text { power } \\
Q_{u}^{e}, \mathrm{kN}\end{array}$ & $\begin{array}{c}\text { Burst occurring } \\
\text { level } \\
Q / Q_{u}^{e}\end{array}$ \\
\hline $\mathrm{ZY}$ & $31-46$ & 4.19 & 140 & 300 & 0.47 \\
\hline $\mathrm{ZX}$ & $44-45$ & 2.29 & 180 & 296 & 0.61 \\
\hline
\end{tabular}

Where $h_{o}$ - plate's working length; $c-$ is the projection length on the longitudinal axis of the most dangerous oblique section element.

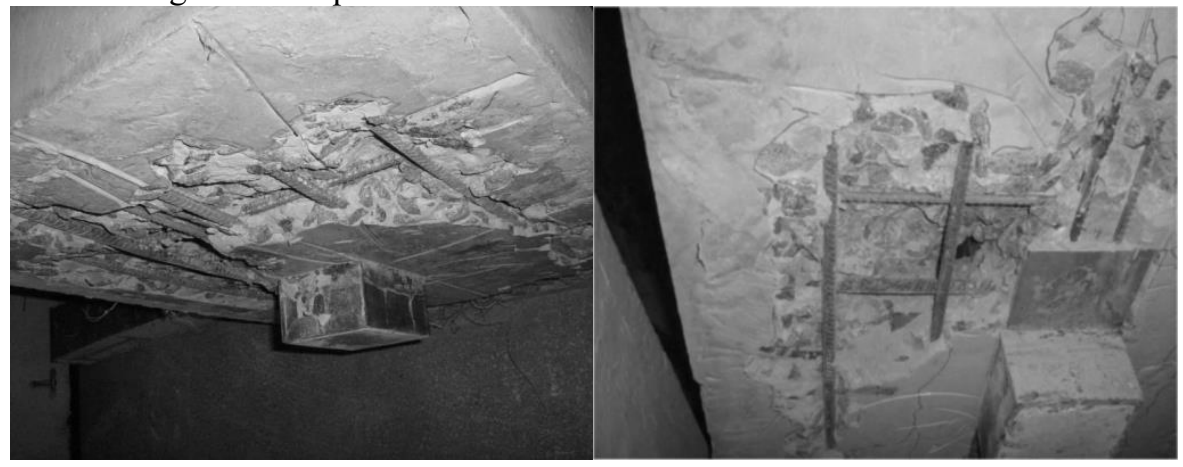

Fig. 7. The samples after testing

Based on the performed theoretical and field experiments calculation methodology for connection nodes between beamless monolithic concrete slab and reinforced concrete column was created.

An introduced procedure of a beamless monolithic slab and a composite column connection node includes two stages:

To check a work of the connection node of a beamless monolithic slab and a composite column during forcing through was developed an improvement of the calculation algorithm according to operative rules using the formula;

A nodal connection between beamless monolithic slab and a composite column calculation for a shear along the column body according to the introduced procedure.

To check a work of a nodal connection for a shear during forcing through it is necessary to determine a length of a design perimeter, using the net formula:

$$
u_{i}=2(a+b)+4 \pi h_{o}
$$

Where $a, b$ - reinforced concrete column geometric sizes; $h_{o}$-working length of the plate.

If applied loading is uneven, a bending moment of plates occur. It is counted in formulas to determine eccentricity of axes $\mathrm{Y}$ and $\mathrm{Z}$.

$$
\left.\begin{array}{l}
e_{y}=\frac{M_{e d y}}{V_{e d}} \\
e_{z}=\frac{M_{e d y}}{V_{e d}}
\end{array}\right\}
$$


Where $\boldsymbol{e}_{\boldsymbol{y}}$ and $\boldsymbol{e}_{z}-$ eccentricity of axes Y and Z;

$M_{e d y}$ - bending moment, acting in the plate on axis $\mathrm{Y}$;

$M_{e d z}$ - bending moment, acting in the plate on axis Z;

$V_{e d}$ - total lateral force acting on the estimated length of the perimeter.

To determine geometric parameters of the forcing through pyramid perimeter the next formulas can be used:

$$
\left.\begin{array}{l}
b_{x}=a+4 \cdot h_{o} \\
b_{z}=b+4 \cdot h_{o}
\end{array}\right\}
$$

Where $a, b$-geometric sizes of reinforced concrete column;

$h_{o}$-working length of the plate. formula:

Loading eccentricity for columns with a rectangular cut is determined using the next

$$
\beta=1+1.8 \sqrt{\left(\frac{e_{y}}{b_{z}}\right)^{2}+\left(\frac{e_{z}}{b_{y}}\right)^{2}}
$$

If the loading eccentricity is less than 1.15 it is necessary to assume 1.15 and determine total shear force acting on the critical perimeter length:

$$
\vartheta_{x}=\beta \frac{V_{E d}^{2}}{u_{i} d}
$$

To determine a ratio of reinforcement assume the next coefficient:

$$
k=1+\sqrt{\frac{200}{d}}
$$

The coefficient shouldn't be more than 2 .

Ratio of reinforcement is equal to:

$$
\rho_{1}=\sqrt{\rho_{1 x}+\rho_{1 y}} \leq 0.02
$$

To determine hardness of a plate without shear reinforcement against forcing through By reinforcement (using the formula introduced by author) [13]:

$$
V_{R d, s} \leq 1.125 \cdot f_{c t d} \cdot u \cdot h \cdot \sqrt{1.1+0.7 \rho}
$$

By concrete:

$$
V_{R d, c}=0.4 \cdot f_{c t d}
$$

The larger value is accepted as calculated.

The calculation algorithm for ceiling slabs under bursting by a column was performed in high level programming language Object Pascal in Delphi environment.

According to the algorithm a computer program was developed using programming language Visual Basic for Applications (VBA). The language is used for applications intended to manipulation of databases and users' interface setup development. VBA is a 
structured high-level programming language. General principles of object-oriented programming are implemented in VBA language.

Software development stages:

1. Issue statement

- The purpose of the software is to check the connection between monolithic beamless non-capital overlap and reinforced columns for the shear using the proposed formula.

2. Issue analysis and design

- At this step inputs and results were determined, revealed constraints on their values, made a formal description of the problem and the mathematical model suitable for solving the problem using computer.

3. Development and the algorithm selection

- Based on the mathematical description of the problem the solving algorithm was created.

4. Design if the general program structure

- The solving model was created with further specification and division into subprograms, defined the software architecture and the way of data storage.

5. Coding

- According to the algorithm software was developed using Visual Basic for Applications (VBA). This programming language is used for applications development, used for interacting with data bases and adjusting the user's interface. VBA is a structured high level programming language. In the VBA language the general principles of object-oriented programming are implemented.

6. Software adjustment and testing

- Performed a verification check of the calculation of connection nodes between monolithic beamless non-capital overlap and reinforced columns for the shear.

7. Results analysis

- Actual results meet the experiment data results.

A programming module used for junction of beamless monolithic slab and a composite column during forcing through testing is shown below (using introduced procedure:

As stated above, it is necessary to perform a calculation of the junctions along the column body according to the procedure.

To determine optimal field performances of rebar the europium method of bracing calculations was used. The method is known as a Concrete Capacity Method.

It includes a concept of hardness estimation using partial safety coefficients.

The main differences of the method are:

Differentiation between collapses mode: an extraction form concrete or steel collapse.

Differentiation between safety coefficients, based on different types of collapse;

According to the method an algorithm of junction between a beamless monolithic slab and a composite column during forcing through calculation along the column body was introduced (figure 8).

According to the algorithm a software program was developed to automate the calculation process (figure 9). 


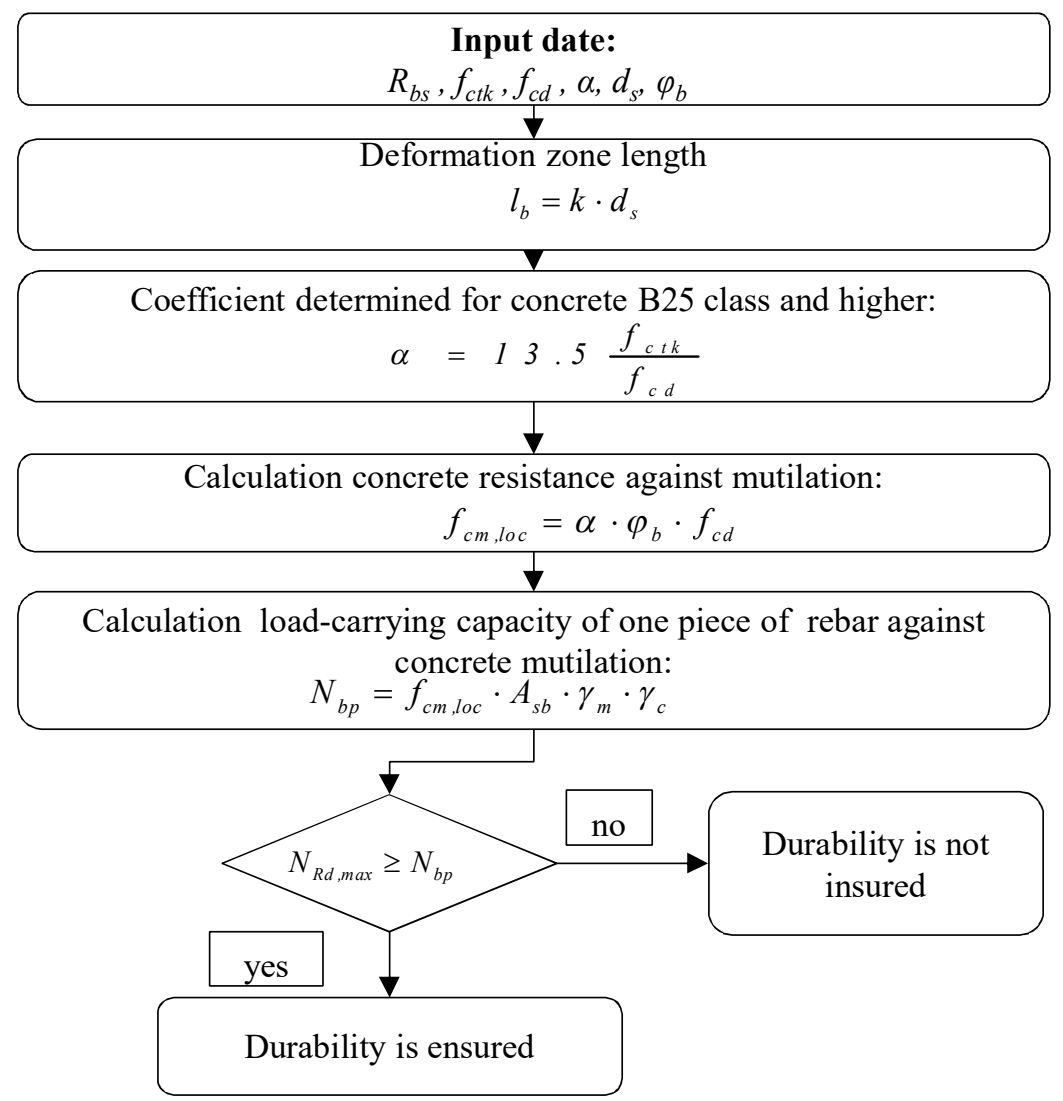

Fig. 8. The algorithm of a junction between a beamless monolithic slab and a composite column during forcing trough calculation (according to the introduced procedure)

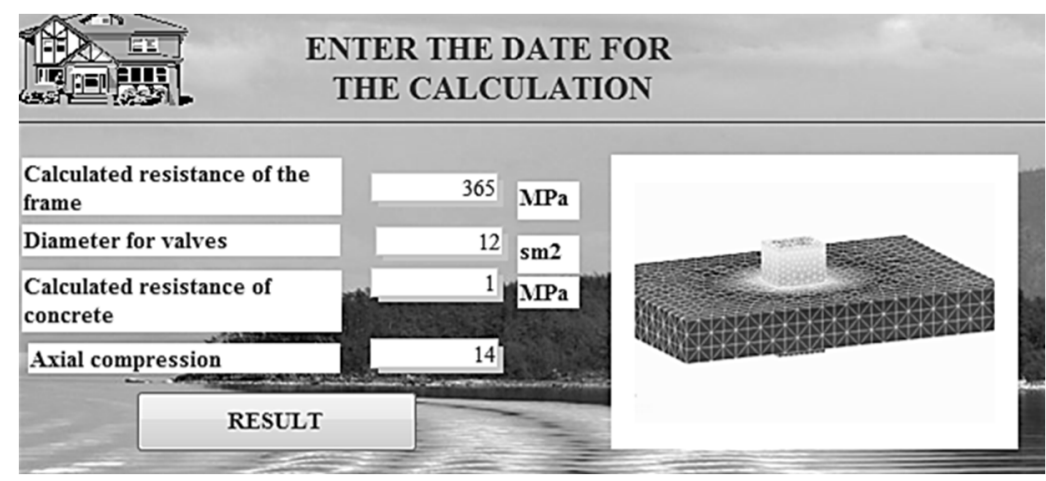

Fig. 2. Software interface of a junction between a beamless monolithic slab and a composite column during forcing through calculation (according to the introduced procedure) calculation

\section{Conclusions}

1. New constructive solutions of the junction of the monolithic reinforced concrete beams with non-beam overlap with steel reinforced concrete columns offer the possibility of redistribution of the bending moment in comparison with the acting analogues. 
2. The model of the stress-strain state is developed and made calculations of the joints between monolithic reinforced concrete non-beam overlap with steel reinforced concrete column by the finite element method is implemented in the Femap software environment. It takes into account the concrete and reinforcement work characteristics, which allows to increase the bearing capacity by $10 \%$.

3. The proposed engineering method for calculating the junction points of monolithic bezel-faced ceilings with steel-reinforced concrete columns, taking into account the features of the stress-strain state, gives more accurate calculation results in comparison with the current norms. The difference between the calculation results for the current and proposed method was $5 \%$.

4. The methodology of calculating the proposed connections includes two stages of calculation: calculation for shear fraction under pressing-through and shearing action along the scape provides the structure load-bearing capacity.

5. The calculation algorithm implemented in Visual Basic for Applications is developed to ensure the accuracy of the engineering calculations based on the method developed by the authors.

\section{References}

1. M.A. Eder, R.L. Vollum, A.Y. Elghazouli, Eng. Struct., 36, 239 - 257 (2012).

2. A.S. Gorodetskiy, I.D. Evzerov, Computer models of structures, K.:Fakt, 344 (2006).

3. R.A. Kanishchev, Mag. of Civ. Eng., 4(64), 59-68 (2016).

4. A.V. Perelmuter, V.I. Slivker, Calculation models of structures and the possibility of their analysis, Stal, 710 (2011).

5. D.G. Shymkovich, Calculation of structures in MSC Nastran for Windows, M: DMK Press. 447 (2003).

6. A.A. Pisano, Fuschi, P., D.D. Domenico, Comp. \& Struct., 160, 42-55 (2015).

7. N.I. Vatin, A.D. Ivanov, Pairing of columns and slabs without edges and without capitals monolithic in a reinforced concrete frame building, Sankt-Peterburg, 82 (2006).

8. D. Zenunovica, R. Folic, Eng. Struct., 40, 466-478 (2012).

9. V.O. Semko, T.A. Dmitrenko, The unassembled knot of the connection of a monolithic bulkhead floor with columns of channels, Pat. 41483 Ukrayina, MPK E 04 B 5/32, Bul. 6, 4 (2009).

10. V.O. Semko, T.A. Dmitrenko, Connection unit of monolithic unbaked bulkhead overlap with columns of channels, Pat. 48566 Ukrayina, MPK E 04 B 5/32, Bul. 10, 4 (2009).

11. V.O. Semko, T.A. Dmitrenko, A.O. Dmitrenko, Connection unit of monolithic overlap with steel-reinforced concrete columns, Pat. 59155 Ukrayina, MPK E 04 B 5/32 (2006.1), Bul., 9, 4 (2011).

12. S.Yu. Fialko Mag. of Civ. Eng, 5 (40), 116-124 (2013).

13. T. A. Dmitrenko, A. O. Dmitrenko, T. M. Derkach, Computer simulation of robots joints for design on the punching shear, Resource-efficient technologies in the construction complex of the region, 232-237 (2014). 